\title{
CONSUMER INNOVATIVENESS DAN CONSUMER ATTITUDE DENGAN SELF CONGRUITY SEBAGAI VARIABEL MEDIASI \\ PADA KONSUMEN GREEN SKINCARE
}

\author{
Kristiningsih $^{1}$, Sri Hartini ${ }^{2}$, Indrianawati Usman ${ }^{3}$ \\ 1) Universitas Wijaya Kusuma Surabaya 2,3) Universitas Airlangga
}

\begin{abstract}
Innovation is something that is important for businesses to survive in the era of competition. Innovation allows companies to continue to make and improve their offerings, and these offers can be implemented in business only if the customer considers the product to be innovative. This study aimed to examine the effect of consumer innovation on consumer attitudes with self-congruity as a mediating variable. The study was conducted on consumers of green skincare products in East Java. To test the hypothesis, a structural Equation Model analysis was performed using WARP PLS. The results showed that there was a positive influence between consumer innovativeness on self-congruity and consumer attitude.
\end{abstract}

Kata kunci : consumer innovativeness, consumer attitude, self congruity Korespondensi $\quad$ : kristiningsih@uwks.ac.id

\section{PENDAHULUAN}

Tampil baik secara fisik merupakan keinginan dari individu. Meningkatnya keinginan seseorang untuk menjadi lebih baik dibuktikan dengan adanya fenomena banyaknya orang yang mulai berbondongbondong mengunjungi klinik perawatan kulit (skincare) untuk mendapatkan bantuan profesional sehingga membuat dirinya menjadi lebih ideal dari sisi penampilan.

Persaingan dalam industri skincare pun semakin tajam. Banyak klinik skincare menawarkan produk dan jasa yang berbeda dari penawaran yang sudah ada sebelumnya. Maka inovasi menjadi syarat penting agar usaha ini dapat memenuhi keinginan pelanggan pelanggannya dalam jangka panjang.
Service innovation didefinisikan sebagai tambahan layanan dari layanan yang ada (inceremental improvements to existing services). Konsep consumer innovativeness mencerminkan sejauh mana pelanggan mengevaluasi dimensi penawaran produk/jasa dengan penuh arti, yang berbeda dari alternatif penawaran yang sudah ada. Consumer innovativeness memang tidak mudah dilakukan namun semakin dipertimbangkan.Dimensi consumerservice innovativeness terdiri dari administration, interior fasilities, exterior facilities, servicescore, employee, technology dan responsiveness. (Ali \& Paswan, 2009).

Inovativeness mengacu pada sejauh mana pelangganmengadopsi inovasi lebih awal dari pelanggan lain tergantungpada difusi teori inovasi. Personal innovation, 
menunjukkan kecenderunganseorang individu untuk mencoba produk dan teknologi baru . (Al-Jabri, I., \& Sohail, 2012)

Selain itu, innovativeness menjadi faktor pentingsecara positif mempengaruhi perilaku (Blake, Neuendorf, \& Valdiserri dalam Al-Jabri, I., \& Sohail, 2012)).Individu dengan innovativeness yang tinggi lebih penasaran, dinamis danmereka lebih terbuka untuk mencoba hal-hal baru . Oleh karena itu, diharapkan konsumen yang inovatif secara pribadimemiliki sikap yang lebih positif terhadap layanan baru ini.(Al-Jabri, I., \& Sohail, 2012).

Menurut Srejesh (2015) saat pelanggan merasakan inovasi dari jasa, yang berasal dari berbagai aspek / dimensi dari services innovation, konsumen akan mengembangkan perasaannya nilai simbolis bagi konsumen tersebut (Fu \& Elliott, 2013). Elemen simbolis ini timbul dari inovasi layanan (services innovativeness) yang ditawarkan yang menjadi alasan utama konsumen mengadopsi jasa tersebut (Castaño, Sujan, Kacker, \& Sujan, 2008). Jika layanan ini mampu membangkitkan perasaan senang dan konsumen, maka proses berpikir konsumen akan menerima inovasi jasa karena aspek simbolis, mereka akan mengintepretasikannya sebagai stereotip dari konsep diri mereka maka akan mempengaruhi Self-congruity konsumen.

Kang et al. menemukan bahwa self congruity memiliki dampak positif pada evaluasi atas jasa. (Kang et al., 2012). Ketika konsumen mengidentifikasi bahwa inovasi jasa kongruen dengan citra dirinya maka konsumen akan setuju bahwa obyek jasa tersebut mewakili identitas mereka, dan dengan demikian, membantu mereka untuk membentuk sikap (attitude) yang menguntungkan (positif) terhadap jasa tersebut.

Fenomena yang terjadi pada konsumen produk/jasa skincare saat ini adalah bahwa konsumen mulai menyadari akan bahan yang digunakan. Isu mengenai bahaya zat mercure

dalam penyalahgunaan produk skincare menjadi sebuah ketakutan tersendiri bagi konsumen. Sehingga keamanan bahan baku menjadi sesuatu yang penting.

Beberapa inovasi muncul untuk menggunakan bahan bahan alami dalam produk/jasa skincare. Klinik Skincare memberikan alternatif melalui setiap penggunaan bahan bakunya yang herbal dalam setiap perawatan yang dilakukan guna memastikan produk tidak mengandung bahan berbahaya. Inovasi itulah yang kemudian disebut sebagai Green Skincare.

Penelitian ini bertujuan untuk mengetahui pengaruh consumer innovativeness terhadap consumer attitude dengan self congruity sebagai variabel mediasi pada konsumen green skincare.

\section{METODE PENELITIAN}

\section{Pendekatan Penelitian}

Penelitian ini adalah penelitian kuantitatif, yaitu penelitian yang menekankan analisisnya pada data numerical atau angka yang diperoleh dengan metode statistik serta dilakukan pada penelitian inferensial atau dalam rangka pengujian hipotesis sehingga diperoleh signifikansi hubungan antara variabel yang diteliti.(Ghozali, 2013)

Populasi dan Sampel

Populasi dalam penelitian ini adalah konsumen Pengguna jasa Skincare di Jawa Timur. Dipilih beberapa kota besar di Jawa Timur dimana pertumbuhan jasa Skincare pesat (berdasarkan hasil wawancara dengan penyedia jasa skincare), yaitu Surabaya, Sidoarjo, Gresik, Malang dan Kediri dan Madiun. Populasi dipilih berdasarkan karakteristik tertentu. Maka digunakan teknik purposive sampling dengan kriteria sebagai berikut :

a. Responden adalah pengguna green skincare

b. Berumur 17 tahun ke atas 
Definisi Operasional variabel

1. Consumer innovativeness:penilaian (evaluasi) konsumen atas inovasi dari dimensi penawaran jasa skincare yang dirasakan oleh konsumen berbeda dari alternative yang sudah ditawarkan sebelumnya (Zolfagharian dan Paswan, 2009). Digunakan 7 indikator untuk mengukur consumer innovativeness

2. Self Congruity adalah kesesuaian antara citra / konsep diri konsumen dengan citra dari jasa skincare yang inovatif (Jamal dan Goode, 2001: Sirgy, 1982: Srejesh dan Sahoo, 2015). Digunakan 5 indikator untuk mengukur self congruity.

3. Consumer Attitude adalah kecenderungan konsumen untuk mengevaluasi jasa/produk green skincare dengan cara mendukung (positif) atau tidak mendukung (negatif) secara konsisten. (Assael, 2010). Digunakan 3 indikator untuk mengukur consumer attitude.

Teknik Analisis

Menguji hubungan kausalitas antar variabel independen (consumer innovativeness), variabel mediasi (self congruity) dan variabel dependen (consumer attitude) digunakan alat analisis statistic yaitu Structural Equation Model (SEM) berbasis varian dengan program WARP Partial Least Square ver 6.0. Analisis SEM dilakukan untuk melihat arah dan signifikansi besaran/ koefisien jalur dari masing masing variabel.

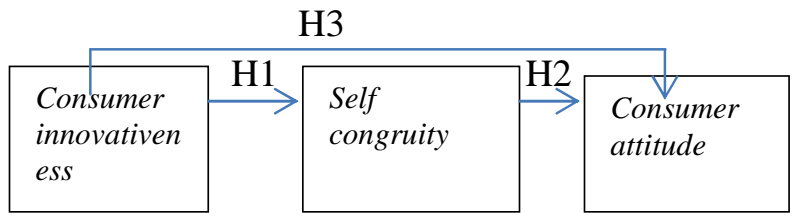

Gambar 1. Model Analisis penelitian

\section{PEMBAHASAN}

Hasil analisis data dalam penelitian ini diringkas dalam table berikut ini:

Tabel 1Hasil estimasi path coefficients Sumber : Data diolah dengan WarpPLS 6.0

\begin{tabular}{lccc}
\multicolumn{1}{c}{ Hipotesis } & $\begin{array}{c}\text { Path } \\
\text { coeffici } \\
\text { ents }\end{array}$ & $\begin{array}{c}p- \\
\text { value }\end{array}$ & $\begin{array}{c}\text { Keterang } \\
\text { an }\end{array}$ \\
\hline $\begin{array}{l}\text { Consumer } \\
\text { Innovativeness } \\
\text { terhadap Self } \\
\text { Congruity (H1) }\end{array}$ & 0,476 & $\begin{array}{c}<0,0 \\
01\end{array}$ & Sig \\
\hline $\begin{array}{l}\text { Self Congruity } \\
\text { terhadap }\end{array}$ & 0,10 & 0,038 & Sig \\
$\begin{array}{l}\text { Attitude Toward } \\
\text { Skincare (H3) }\end{array}$ & & & \\
\hline $\begin{array}{l}\text { Consumer } \\
\text { Innovativeness }\end{array}$ & 0,146 & 0.003 & Sig \\
terhadap & & & \\
$\begin{array}{l}\text { Attitude Toward } \\
\text { Skincare (H5) }\end{array}$ & & & \\
\hline
\end{tabular}

Hasil penelitian yang dilakukan menunjukkan bahwa nilai $\mathrm{p}$ value consumer innovativeness terhadap self congruity memiliki nilai signifikansi sebesar $<0,001$ atau nilai signifikansi kurang dari 0,05. Berdasarkan hasil tersebut dapat dinyatakan bahwa service innovativeness berpengaruh positif pada self congruity, sehingga hipotesis 1 yang menyatakan consumer innovativeness berpengaruh positif terhadap self congruityditerima. Nilai path coefficient adalah sebesar 0,476 (positif). Hasil tersebut menjelaskan bahwa ketika penilaian konsumen atas jasa skincare yang terus menciptakan dan memperbaiki penawaran semakin tinggi maka konsumen akan menilai semakin tinggi pula kesesuaian jasa skincare yang inovatif itu dengan konsep diri konsumen.

Penelitian ini mendukung penelitian yang dilakukan oleh Srejesh (2015) yang menyatakan bahwa saat pelanggan merasakan 


\section{Balance: Economic, B usiness, Management, and Accounting J ournal Vol. XVII No. 1 | Bulan J anuari Tahun 2020}

inovasi dari jasa, yang berasal dari berbagai aspek/ dimensi daari services innovation, konsumen akan mengembangkan perasaan dan kesenangan saat memikirkannya sebagai potensi dari nilai simbolis bagi konsumen tersebut

Hasil penelitian yang dilakukan menunjukkan bahwa nilai $\mathrm{p}$ value untuk self congruityterhadap attitude toward skincare memiliki nilai signifikansi sebesar 0,038 atau nilai signifikansi kurang dari 0,05 . Berdasarkan hasil tersebut dapat dinyatakan bahwa self congruity berpengaruh positif pada attitude toward skincare, sehingga hipotesis 2yang menyatakan bahwa self congruity berpengaruh positif terhadap consumerattitude toward skincare adalah diterima..Nilai path coefficient adalah sebesar 0, 224 (positif). Hasil tersebut menjelaskan semakin tinggi kesesuaian jasa skincare yang inovatif dengan konsep diri konsumen maka semakin baik sikap konsumen atas jasa skincare tersebut.

Hasil penelitian ini mendukung penelitian yang dilakukan oleh Sirgy (1985) yang menyatakan bahwa self congruity mendahului sikap konsumen terhadap produk dan perilaku belanja mereka. Pendapat lain dikemukan oleh Kang et all (2012) yang menyatakan bahwa self congruity berpengaruh positif terhadap evaluasi konsumen atas jasa yang dikonsumsinya

TABEL 2. Perhitungan Variance Accounted For (VAF) Variabel Self Congruity

\begin{tabular}{|c|c|}
\hline $\begin{array}{l}\text { Pengaruh tidak langsung }=0,476 \times 0,10 \\
(\mathrm{SI} \rightarrow \mathrm{SC}=0,476 ; \mathrm{SC} \rightarrow \mathrm{ATS}=0,10)\end{array}$ & 0,0476 \\
\hline $\begin{array}{l}\text { Pengaruh langsung } \\
(\mathrm{SI} \rightarrow \mathrm{ATS} ; \text { tanpa memasukkan variabel } \\
\text { mediasi }=0,146)\end{array}$ & 0,146 \\
\hline Pengaruh total $=0,0476+0,416$ & 0,4636 \\
\hline $\begin{array}{l}\mathrm{VAF}=\text { pengaruh tidak langsung/pengaruh } \\
\text { total }=0,0476 / 0,4636\end{array}$ & 0,1026 \\
\hline \multicolumn{2}{|l|}{ Sumber : Data diolah dengan WarpPLS 6.0} \\
\hline $\begin{array}{cccl} & \text { Menurut tabel } & 5.28 & \text { nilai } \\
\text { adalah sebesar } & 0,1026 & (10,26 \%\end{array}$ & $\begin{array}{l}\mathrm{VAF} \\
\text { atau }\end{array}$ \\
\hline
\end{tabular}

dibawah 20\%, sehingga hal ini menunjukkan bahwa self congruitytidak memediasi hubungan antara consumer innovativeness dan consumer attitude toward skincare.

\section{KESIMPULAN}

Hasil penelitian ini dapat disimpulkan sebagai berikut:

1. Consumer innovativeness berpengaruh positif terhadap self congruity

2. Self congruity berpengaruh positif terhadap customer attitude toward skincare

3. Self congruity tidak memediasi hubungan antara consumer innovativeness terhadap consumer attitude.

\section{Implikasi Manajerial}

Inovasi yang dilakukan oleh perusahaan maerupakan salah satu stimuli penting guna menciptakan image congruity yang baik pada produk/ jasa perusahaan, Hasil penelitian menunjukkan pengaruh service innovativeness terhadap self congruity adalah sebesar 47,6\% Maka inovasi jasa menjadi sesuatu yang harus dipikirkan agar konsumen memiliki image yang baik pada jasa/produk yang dipasarkan. Inovasi dikatakan berguna bila konsumen menilai layanan perusahaan benar benar inovatif bagi konsumen. Maka perlu dibuat strategi untuk meningkatkan inovasi jasa perusahaan yang sesuai dengan harapan konsumen,

\section{SARAN}

Penelitian dilakukan pada responden menggunakan jasa skincare sebelumnya, maka penelitian selanjutnya menggunakan responden yang sudah maupun yang belum berpengalaman, sehingga variabel service experience dapat dimunculkan sebagai salah satu variabel eksogen dalam penelitian untuk mengembangkan lebih lanjut model penelitian ini. 


\section{DAFTAR PUSTAKA}

Ajzen, I., \& Fishbein, M. (1977). AttitudeBehavior Relations: A Theoretical Analysis and Review of Empirical Research, 84(5), 888-918.

Al-Jabri, I. \& Sohail, M. S. (2012). Mobile banking adoption: Application of diffusion of innovation theory. Journal of Electronic Commerce Research, 13(4), 379-391.

Ali, M., \& Paswan, A. (2009). Perceived Service Innovativeness, Consumer Trait Innovativeness and Patronage Intention. Journal of Retailing and Consumer Services, 16, 155-162. https://doi.org/10.1016/j.jretconser.2008 .11 .007

Assael, H. (2002). Consumers Bahaviors and Marketing Action (3rd ed.). Boston Massachussets: Kent Publishing Company.

Eagly, A. (1993). The Psychology of Attitude. Fort Worth TX: Harcourt Brace.

Engel, James F. (1995). Perilaku Konsumen (6th ed.). Jakarta: Binarupa Aksara

Ghozali, I. (2013). Aplikasi Analisis Multivariate dengan Program IBM SPSS 21 (7th ed.). Semarang: Badan Penerbit Universitas Diponegoro.

Hafedh, Ibrahim and Faouzi Najjar. (2008). Assessing the Effects of Self-Congruity , Attitudes and Customer Satisfaction on Customer Behavioural Intentions in Retail Environment. Marketing Intelligence \& Planning, Vol. 26 No. https://doi.org/10.1108/0263450081086 0638

Hair, J. (2010). Multivariate Data Analysis (7th ed.). Pearson Prentice Hall.

Kotler, Philip \& Keller, K. L. (2016). Marketing Management.

Lonial, S. C., \& Raju, P. S. (2001). The
Impact of Environmental Uncertainty on the Market Orientation - Performance Relationship: A Study of the Hospital. Journal of Economic and Social Research, 3(1), 5-27.

Osgood, C. E., \& Tannenbaum, P. H. (1955). The Principle of Congruity in The Prediction of Attitude Change, 62(1).

Sirgy, M.J. (1999). Toward An Integrated Model of Self-Congruity and Functional Congruity. European Advances in Consumer Marketing, Vol 4, 252-256.

Sirgy, M. J. (1985). Using Self-Congruity and Ideal Congruity to Predict Purchase Motivation, 206, 195-206.

Sirgy, M. J. (1991). Self-Congruity Versus Functional Congruity: Predictors of Consumer Behavior, 363-364.

Sirgy, M. J. (2000). Retail Environment, SelfCongruity, and Retail Patronage: An Integrative Model and a Research Agenda, 2963(99).

Sreejesh, S., Amarnath Mitra, \& Debjani Sahoo. (2015). The Impact of Customer's Perceived Service Innovativeness on Image Congruence, Satisfaction and Behavioral Outcomes. Journal of Hospitality and Tourism Technology, Vol. 6(3), 288-310. https://doi.org/10.1108/JHTT-10-20140061

Sugiyono. (2017). Metode Penelitian

Kuantitatif, Kualitatif, dan $R \& D$. Bandung: CV Alfabeta.

Xin, J. H. (2013). The Role of Brand Image Congruity in Chinese Consumers' Brand Preference. Journal, of Product \& Brand Management.

https://doi.org/10.1108/10610421211203088

Zolfagharian, M. and A. P. (2009). "Perceived Service Innovativeness, 
Balance: Economic, Business, Management, and Accounting J ournal Vol. XVII No. 1 | Bulan J anuari Tahun 2020

Consumer Trait Innovativeness and

Patronage Intention. Journal of $155-162$.

Retailing and Consumer Services, 16(2), 